DE

M E D I C I N A

T R O P I C A L

DE

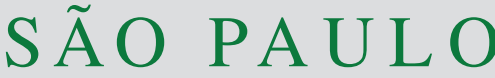

JOURNAL OF THE SÃO PAULO INSTITUTE OF TROPICAL MEDICINE

${ }^{1}$ Universidade Estadual de Londrina, Departamento de Enfermagem, Londrina, Paraná, Brazil

'Universidade Estadual de Londrina, Departamento de Microbiologia, Londrina, Paraná, Brazil

3Universidade Estadual de Londrina, Departamento de Microbiologia, Laboratório de Ecologia Microbiana, Londrina, Paraná, Brazil

${ }^{4}$ Universidade Estadual de Londrina, Departamento de Saúde Coletiva, Londrina, Paraná, Brazil

5Universidade Estadual de Londrina, Departamento de Pediatria e Cirurgia Pediátrica, Londrina, Paraná, Brazil

${ }^{6}$ Universidade Estadual de Londrina, Departamento de Patologia, Análises Clínicas e Toxicológicas, Londrina, Paraná, Brazil

Correspondence to: Gilselena Kerbauy Universidade Estadual de Londrina, Departamento de Enfermagem, Av. Robert Kock, 60, CEP 86039-440, Londrina, PR, Brazil

Tel: $+55433371-2249$

E-mail: gilselena@ hotmail.com

Received: 4 September 2019

Accepted: 18 February 2020

\section{Colonization profile and duration by multi-resistant organisms in a prospective cohort of newborns after hospital discharge}

\author{
Andressa Midori Sakai ${ }^{\circledR}$, Thayla Nadrielly Aparecida Nicolino lensue ${ }^{2}$, \\ Kauana Olanda Pereira1, Renata Lima da Silva1, Leila Garcia de Oliveira \\ Pegoraro', Marta Silva de Almeida Salvador ${ }^{3}$, Renne Rodrigues ${ }^{4}$, Jaqueline \\ Dario Capobiango ${ }^{5}$, Nathália Aparecida Andrade de Souza ${ }^{6}$, Marsileni \\ Pelisson $^{6}$, Eliana Carolina Vespero ${ }^{\circledR 6}$, Lucy Megumi Yamauchi ${ }^{\circledR}$, Marcia \\ Regina Eches Perugini ${ }^{6}$, Sueli Fumie Yamada-Ogatta ${ }^{\circledR 2}$, Edilaine Giovanini \\ Rossetto ${ }^{\circledR}$, Gilselena Kerbauy 1
}

\section{ABSTRACT}

The aim of this study was to determine the spontaneous decolonization period and characteristics in a prospective cohort of newborns colonized by multidrug-resistant organisms, after their discharge from the neonatal intensive care unit. Multidrug resistance is defined as bacterial non-susceptibility to $\geq 1$ agent of $\geq 3$ antimicrobial categories. In total, 618 newborns were included in the study, of which $173(28.0 \%)$ presented a positive culture for multidrugresistant microorganisms, and of these, $52(30.1 \%)$ were followed up in this study. The most frequent intrinsic factors were be born by cesarean section $(86.5 \%)$, prematurity $(84.6 \%)$, and very low birth weight $(76.9 \%)$. The extrinsic factors were having remained hospitalized for an average of 27 days, during which $67.3 \%$ were submitted to invasive procedures and $88.5 \%$ received antimicrobials. The intrinsic and extrinsic factors of newborns were not associated to a decolonization period longer or shorter than 3 months, which was the average period of decolonization found in the present study. From the totality of colonization cultures sampled at hospital discharge, the Gram-negative Extended Spectrum $\beta$-lactamase producing bacteria were the most common, with $28.9 \%$ of babies colonized by Klebsiella spp. The median period of decolonization by multidrug-resistant microorganisms in the newborns population after hospital discharge was 3 months, but was highly dependent on the microbial species, and this period was not associated to any intrinsic and extrinsic factors of the newborn.

KEYWORDS: Premature. Neonatal intensive care. Antimicrobial resistance. Colonization. Decolonization. Very low birth weight.

\section{INTRODUCTION}

The human microbiota composition begins in the maternal uterus ${ }^{1-3}$ and continues with the acquisition of microorganisms in the birth canal and later from maternal skin $^{4}$. This natural process is modified in premature newborns who are usually delivered by cesarean sections ${ }^{5}$, and for whom the contact with the mothers is replaced by care in a neonatal intensive care unit (NICU), in which the babies are more exposed to microorganisms belonging to the hospital setting ${ }^{6,7}$, as well as those of the health professionals ${ }^{8}$. Among the microorganisms in the hospital setting, antimicrobial resistant ones result from the selection pressure triggered by these drugs, widely used in intensive care units ${ }^{9}$, as well as by cross contamination ${ }^{10}$. 
Multidrug-resistant (MDR) bacteria are considered a major threat to public health by the World Health Organization (WHO) due to the therapeutic limitations and high lethality of infections caused by these agents ${ }^{11,12}$, especially in the neonatal population, whose immunological immaturity and fragility of skin barriers favor these infections ${ }^{8}$.

Colonization by MDR increases the risk of infection by these microorganisms ${ }^{13}$. Given this evidence, one can infer that this risk can extend to the domiciliary context when the newborn remains colonized by MDR after discharge. Colonization also poses a risk of MDR transmission to family members ${ }^{14}$ which remains until the moment of decolonization.

The process of decolonization has been studied in adults ${ }^{15-18}$ and is related to the topical use of antiseptics in aqueous formulations, and of antimicrobials in ointments. However, due to the immaturity of the skin barrier, these strategies are not applied to newborns due to the toxicity and systemic absorption potential of these antiseptic antimicrobial agents in this population ${ }^{19}$.

Considering the negative impact of MDR colonization and the knowledge gap regarding the period in which the newborn remains colonized after hospital discharge, the present study aimed to determine the period for spontaneous MDR decolonization in newborns after discharge from a neonatal intensive care unit. In addition, associations of the decolonization period with perinatal and clinical variables during hospitalization were investigated.

\section{MATERIALS AND METHODS}

\section{Study design and setting}

This is a prospective cohort study of newborns colonized by MDR during hospitalization in a neonatal intensive care unit of a university hospital. They were followed up after discharge until decolonization in a 4-year convenience period, from January 2014 to September 2018.

\section{Inclusion and exclusion criteria}

The study population consisted of 1,395newborns, of which 618 met the inclusion criteria as they remained hospitalized in the same unit for a period of more than $72 \mathrm{~h}$ and their mothers agreed to participate in the study. Of these, $28.0 \%(\mathrm{n}=173)$ presented colonization by MDR as shown by positive cultures and were prospectively monitored. Every 30 days, swab samples collected during domiciliary visits or during an ambulatory consultation were cultured until a negative culture for MDR was obtained.
Babies who were readmitted to hospital or died during the period of domiciliary monitoring or outpatient followup were excluded. Losses were considered when swab collection at hospital discharge was not performed; the family moved to a municipality other than the study site; the mother withdrew consent to participate in the study and the contact with mothers was lost due to telephone number and address changes (Figure 1).

The study was carried out in a reference center for highrisk pregnancies and neonatal intensive care. The neonatal unit is composed of a Neonatal Intermediate Care Unit with 20 beds, and a Neonatal Intensive Care Unit (NICU) with ten beds.

\section{Data collection}

The clinical and epidemiological data regarding hospitalization were collected from the medical records of the newborns and analyzing the following variables: sex, type of delivery, birth weight, gestational age, invasive procedures, antimicrobial use, type of breastfeeding and period of hospitalization.

At hospital discharge, swabs were collected for culture (Transystem Stuart collection device, COPAN Diagnostic, Italy); the first set of swabs was collected from the oral, nasal, axillary and inguinal regions, simultaneously; the second set of swabs was collected from the inguinal and rectal regions, simultaneously. Then, swabs were sent to the microbiology laboratory and processed within $72 \mathrm{~h}$.

\section{Microbiology analysis}

The first set of swabs (1) was inoculated into Tryptic Soy Broth (TSB, Oxoid, Cheshire, England) supplemented with $16 \mu \mathrm{g} / \mathrm{mL}$ cefotaxime (TSB-CTX) to select Gram-negative bacilli and TSB supplemented with $6.5 \% \mathrm{NaCl}$ (TSB-NaCl) to select Staphylococcus aureus. The second set of swab (2) was inoculated in TSB-CTX and TSB supplemented with $6 \mu \mathrm{g} / \mathrm{mL}$ vancomycin (TSB-VRE) to select Enterococcus spp. The cultures were incubated at $35^{\circ} \mathrm{C}$ for $24 \mathrm{~h}$. Cultures that did not show growth were maintained for another $24 \mathrm{~h}$. After growth, the bacteria were seeded in Petri dishes containing VRE Agar, Mannitol Salt Agar (MSA) and MacConkey Agar supplemented with $16 \mu \mathrm{g} / \mathrm{L}$ cefotaxime (CTX-MacConkey), that were incubated at $35^{\circ} \mathrm{C}$ for $24 \mathrm{~h}$. Plates that did not show growth in $48 \mathrm{~h}$ were discarded and the culture was considered negative.

The bacterial susceptibility profile to the antimicrobial agents was analyzed by the disc-diffusion technique, as recommended by the Centers for Disease Control and Prevention $^{20}$, considering the Clinical and Laboratory 


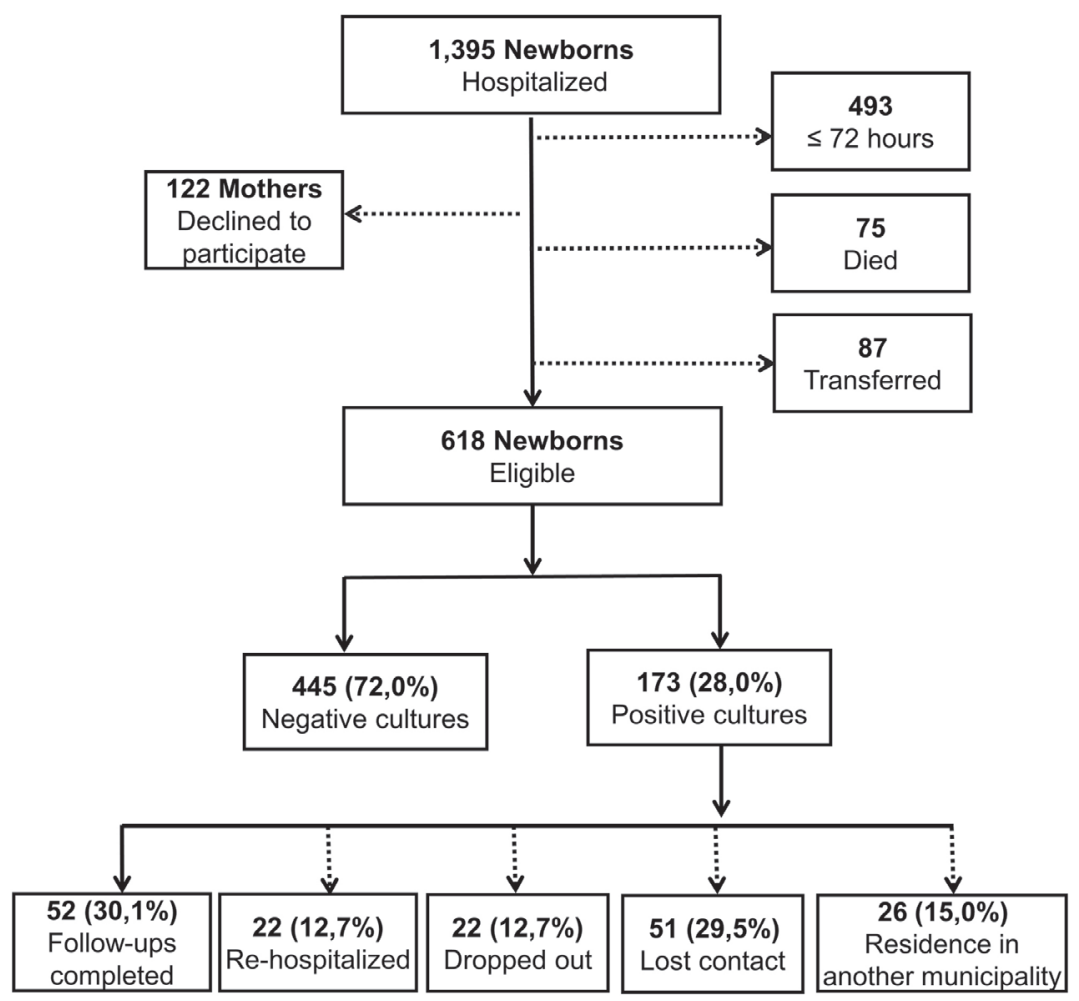

Figure 1 - Flowchart of the study sample design, Parana State, Brazil, 2014-2018.

Standard Institute ${ }^{21-25}$ and European Committee on Antimicrobial Susceptibility Testing ${ }^{26}$, to detect extended spectrum $\beta$-lactamase producing microorganisms (ESBL), performed using the double disc synergism test.

Molecular techniques were not performed as this study did not include the identification of clonal transmission of MDR as an objective ${ }^{20}$.

MDR is defined as a bacterial non-susceptibility to $\geq 1$ agent in $\geq 3$ antimicrobial categories considering: Enterobacteria, Acinetobacter baumannii and Pseudomonas aeruginosa resistant to $3^{\text {rd }}$ or $4^{\text {th }}$ generation cephalosporins or monobactams (Extended Spectrum $\beta$-lactamase ESBL) and carbapenems (Carbapenem resistance - CR); Staphylococcus aureus resistant to methicillin/oxacillin (MRSA) and Enterococcus spp. resistant to vancomycin $(\mathrm{VRE})^{27}$. The Enterobacter spp. and Klebsiella spp. were grouped for consistency in the frequency analysis. After the antimicrobial susceptibility test, the bacteria were stored in $30 \%$ TSB-glycerol at $-20^{\circ} \mathrm{C}$.

The newborns who did not receive antimicrobial therapy for several weeks and who had two repeatedly negative cultures for MDR over two weeks were considered decolonized $^{20}$.

\section{Statistical analysis}

The data were tabulated in Microsoft Office Excel
97-2013 ${ }^{\circledR}$ and analyzed in the Statistical Package for the Social Sciences (SPSS) version 20.0 (IBM, Armonk, New York, USA). The results of the continuous variables are described as mean and standard deviation (SD) or median and interquartile range (ITQ), depending on the distribution of the data. Categorical variables were analyzed using the Pearson Chi-square test. In order to investigate the magnitude of the association between variables, a binary logistic regression was performed to obtain the odds ratio (OR) and 95\% confidence interval $(95 \% \mathrm{CI})$.

\section{Ethical considerations}

This research was approved by the Ethics Committee on Research involving Humans (CAAE No. 15415413.4.0000.5231) of the Universidade Estadual de Londrina.

\section{RESULTS}

Among the newborns followed until decolonization $(n=52)$, most of them were male $(53.8 \%)$ and born by cesarean section $(86.5 \%)$. Regarding the gestational age, $84.6 \%$ of the infants were premature, $34.6 \%$ were born before 30 weeks, $44.2 \%$ were between 31 and 34 weeks, and $21.2 \%$ were born after 34 weeks. In total, $76.9 \%$ of the newborns were born with low weight, while $23.1 \%$ were 
within the normal range ( $>2,500 \mathrm{~g})$. At the time of hospital discharge, $48.1 \%$ of the infants were exclusively breastfed.

The hospitalization period presented a median of 27 days $(8 \pm 124)$ and during this period, $88.5 \%$ of the infants received antimicrobial therapy, with a median of 28 days of use $(16 \pm 40)$. All the infants treated with antimicrobials received $\beta$-lactam class antibiotics, with a median of 10 days $(1 \pm 36)$, the most frequent of which were penicillin and oxacillin.

In relation to newborns who had an invasive procedure $(n=35), 65.4 \%$ required central venous catheters $(\mathrm{CVC})$, $46.2 \%$ mechanical ventilation (MPV) and $71.4 \%$ underwent more than one procedure.

The perinatal and clinical variables of the newborns during hospitalization were not associated to decolonization periods of more or less than 3 months, however, decolonization $\geq 3$ months was more frequent among infants born before 35 weeks (91.4\%), with low birth weight $(<2000 \mathrm{~g}, 87.0 \%)$, and hospitalized for more than 10 days (Table 1$)$.

Gram-negative ESBL-producing bacteria were the most frequently isolated MDR in the colonization cultures of babies at discharge (Figure 2).

The MDR decolonization period after hospital discharge ranged from 1 to 9 months, with a median of 3 months (Figure 3).

The mean period of MDR decolonization corresponded to 5.2 months for Escherichia coli ESBL-producer, 4 months for ESBL-producing Serratia marcescens, 3 months for Klebsiella spp. ESBL/CR, ESBL-producing Pseudomonas aeruginosa, MRSA and Serratia marcescens CR, 2 months for Acinetobacter baumannii CR, 1.6 months for ESBL-producing Enterobacter spp., 1.5 months for ESBL-producing Citrobacter freundii, and 1 month for Enterobacter spp. CR.

Regarding the maximum period of decolonization related to bacterial species, carbapenem-resistant bacteria colonized infants up to 2 months after discharge, and ESBL-producing E. coli and ESBL-producing Klebsiella spp. continued to colonize infants up to 8 months in the domiciliary context (Figure 4).

\section{DISCUSSION}

Little is known about the period of MDR decolonization after discharge, both in infant and adult populations. The scarcity of studies can be justified by the methodological complexity of a follow-up of newborns after hospital discharge, as many factors hamper studies of this nature, such as the operational costs, deaths, rehospitalizations, follow-up in the domiciliary environment, data collection and biological samples collection. These difficulties were corroborated in the present study, where the follow-up of $70 \%$ of the newborns colonized at discharge was interrupted. Even with these losses and exclusions, our study had an important neonatal population of 52 newborns followed-up to decolonization in a study lasting 4 years.

Among the results reported in the literature that address the theme of our study, two analyzed MDR colonization in feces collected from the children. Furthermore, these studies were limited to the monitoring of decolonization by ESBL-producing bacteria, excluding those resistant to carbapenems and MRSA $^{14,28}$, which were analyzed in the present study.

One of the studies cited above was conducted in Austria in a prospective study that followed-up 25 infants colonized by ESBL producing bacteria after discharge from an NICU. In that study Klebsiella spp. was the most prevalent and remained for up to 1 year, followed by Serratia marcescens, with colonization remaining until the $4^{\text {th }}$ month after discharge. E. coli was isolated from a single newborn who remained colonized for $1 \mathrm{month}^{28}$. Our study has also shown that ESBL producing Klebsiella spp. was the most frequent MDR and continued colonizing the babies for an average of 3 months and a maximum period of 8 months. Although ESBL producing S. marcescens was less frequent in our study, the decolonization period was close to the aforementioned study. Finally, ESBL producing E. coli was more frequent and remained colonizing infants for longer periods after discharge when compared to the results of these authors.

Another research detected ESBL-producing Klebsiella pneumoniae in the feces of 51 infants who were domiciliary followed-up after hospital discharge from an NICU. These authors showed that the period of decolonization by this bacterium was on average 12.5 months after hospital discharge, with the maximum period for decolonization being 23.5 months. They also found that antimicrobial treatment and birth by cesarean section are risk factors for longer periods of colonization by ESBL-producing K. pneumoniae ${ }^{14}$. In this study, the perinatal and clinical variables of infants were not related to the decolonization period of 3 months or less for any of the microorganisms studied. These disagreements can be explained by differences in sampling methods for culture.

Adult decolonization has been more frequently studied using different sampling sites ${ }^{15-18}$. A multicenter study performed in 13 European hospitals using nasal and perineal swab collection revealed that the period for MDR decolonization after discharge from the NICU was 4.8 months, and the study has also included patients 
Table 1 - Association of perinatal and clinical variables of newborns $(n=52)$ during hospitalization with the decolonization period after discharge from a neonatal unit, Parana State, Brazil, 2014-2018.

\begin{tabular}{|c|c|c|c|c|c|c|}
\hline \multirow[b]{2}{*}{ Neonatal Variables } & \multicolumn{2}{|c|}{ Newborns $(\mathrm{N}=52)$} & \multirow[b]{2}{*}{ OR } & & & \multirow[b]{2}{*}{$p$-value } \\
\hline & $\begin{array}{l}\text { Decolonization } \\
\geq 3 \text { months }\end{array}$ & $\begin{array}{l}\text { Decolonization } \\
<3 \text { months }\end{array}$ & & \multicolumn{2}{|c|}{ Cl 95\% } & \\
\hline \multicolumn{7}{|l|}{ Gender } \\
\hline Female & $10(43.5)$ & $14(48.3)$ & 0.82 & 0.27 & 2.48 & 0.730 \\
\hline Male & $13(56.5)$ & $15(51.7)$ & 1.00 & & & \\
\hline \multicolumn{7}{|l|}{ Type of Birth } \\
\hline Normal & $3(13.0)$ & $4(13.8)$ & 1.00 & & & \\
\hline Cesarean section & $20(87.0)$ & $25(86.2)$ & 1.07 & 0.21 & 5.33 & 0.937 \\
\hline \multicolumn{7}{|l|}{ Gestational Age } \\
\hline$<30$ weeks & $10(43.6)$ & $8(27.6)$ & 8.75 & 0.88 & 86.60 & 0.064 \\
\hline 31-34 weeks & $11(47.8)$ & $12(41.4)$ & 6.42 & 0.68 & 60.84 & 0.105 \\
\hline 35-36 weeks & $1(4.3)$ & $2(6.9)$ & 3.50 & 0.15 & 84.69 & 0.441 \\
\hline$\geq 37$ weeks & $1(4.3)$ & $7(24.1)$ & 1.00 & & & \\
\hline \multicolumn{7}{|l|}{ Birth Weight } \\
\hline$<1,000 \mathrm{~g}$ & $3(13.0)$ & $6(20.7)$ & 1.50 & 0.22 & 10.08 & 0.677 \\
\hline $1,000-1,499 \mathrm{~g}$ & $7(30.4)$ & $4(13.8)$ & 5.25 & 0.87 & 31.55 & 0.070 \\
\hline $1,500-1,999 \mathrm{~g}$ & $10(43.6)$ & $7(24.1)$ & 4.29 & 0.84 & 21.76 & 0.079 \\
\hline $2,000-2,499 \mathrm{~g}$ & 0 & $3(10.3)$ & NA & & & \\
\hline$>2,500 \mathrm{~g}$ & $3(13.0)$ & 9 (31.1) & 1.00 & & & \\
\hline \multicolumn{7}{|l|}{ Discharge Weight } \\
\hline$<1,000 \mathrm{~g}$ & 0 & 0 & NA & & & \\
\hline $1,000-1,499 \mathrm{~g}$ & 0 & $1(3.4)$ & NA & & & \\
\hline $1,500-1,999 \mathrm{~g}$ & $14(60.9)$ & $12(41.4)$ & 3.21 & 0.81 & 12.75 & 0.098 \\
\hline $2,000-2,499 \mathrm{~g}$ & $5(21.7)$ & $5(17.2)$ & 2.75 & 0.51 & 14.86 & 0.240 \\
\hline$>2,500 \mathrm{~g}$ & $4(17.4)$ & $11(37.9)$ & 1.00 & & & \\
\hline \multicolumn{7}{|c|}{ Breastfeeding on Discharge } \\
\hline Exclusive & $12(42.9)$ & $13(54.2)$ & 1.00 & & & \\
\hline Not exclusive & $11(57.1)$ & $16(45.8)$ & 0.75 & 0.25 & 2.23 & 0.599 \\
\hline \multicolumn{7}{|l|}{ Hospitalization Period } \\
\hline$\leq 10$ days & $2(8.7)$ & $6(20.7)$ & 1.00 & & & \\
\hline$>10$ days & $21(91.3)$ & $23(79.3)$ & 2.74 & 0.49 & 15.09 & 0.247 \\
\hline \multicolumn{7}{|l|}{ Invasive Procedures } \\
\hline Yes & $14(60.9)$ & $21(72.4)$ & 0.59 & 0.18 & 1.91 & 0.380 \\
\hline No & $9(39.1)$ & $8(27.6)$ & 1.00 & & & \\
\hline \multicolumn{7}{|l|}{ Number of Procedures } \\
\hline None & $9(39.1)$ & $8(27.6)$ & 1.00 & & & \\
\hline 1 & $5(21.8)$ & $5(17.2)$ & 0.88 & 0.19 & 4.24 & 0.883 \\
\hline 2 or more & $9(39.1)$ & $16(55.2)$ & 0.50 & 0.14 & 1.75 & 0.279 \\
\hline \multicolumn{7}{|l|}{ Antimicrobial Therapy } \\
\hline Yes & $21(91.3)$ & $25(86.2)$ & 0.59 & 0.09 & 3.58 & 0.571 \\
\hline No & $2(8.7)$ & $4(13.8)$ & 1.00 & & & \\
\hline \multicolumn{7}{|l|}{ Number of Classes } \\
\hline None & $2(8.7)$ & $4(13.8)$ & 1.00 & & & \\
\hline 1 class & 0 & 0 & NA & & & \\
\hline 2 classes & $13(56.5)$ & $16(55.2)$ & 1.62 & 0.25 & 12.45 & 0.607 \\
\hline 3 classes or more & $8(34.8)$ & $9(31.0)$ & 1.78 & 0.25 & 12.45 & 0.562 \\
\hline \multicolumn{7}{|l|}{ Period of Use } \\
\hline$<15$ days & $9(39.1)$ & $12(41.4)$ & 1.00 & & & \\
\hline$\geq 15$ days & $14(60.9)$ & $17(58.6)$ & 1.09 & 0.36 & 3.36 & 0.870 \\
\hline
\end{tabular}




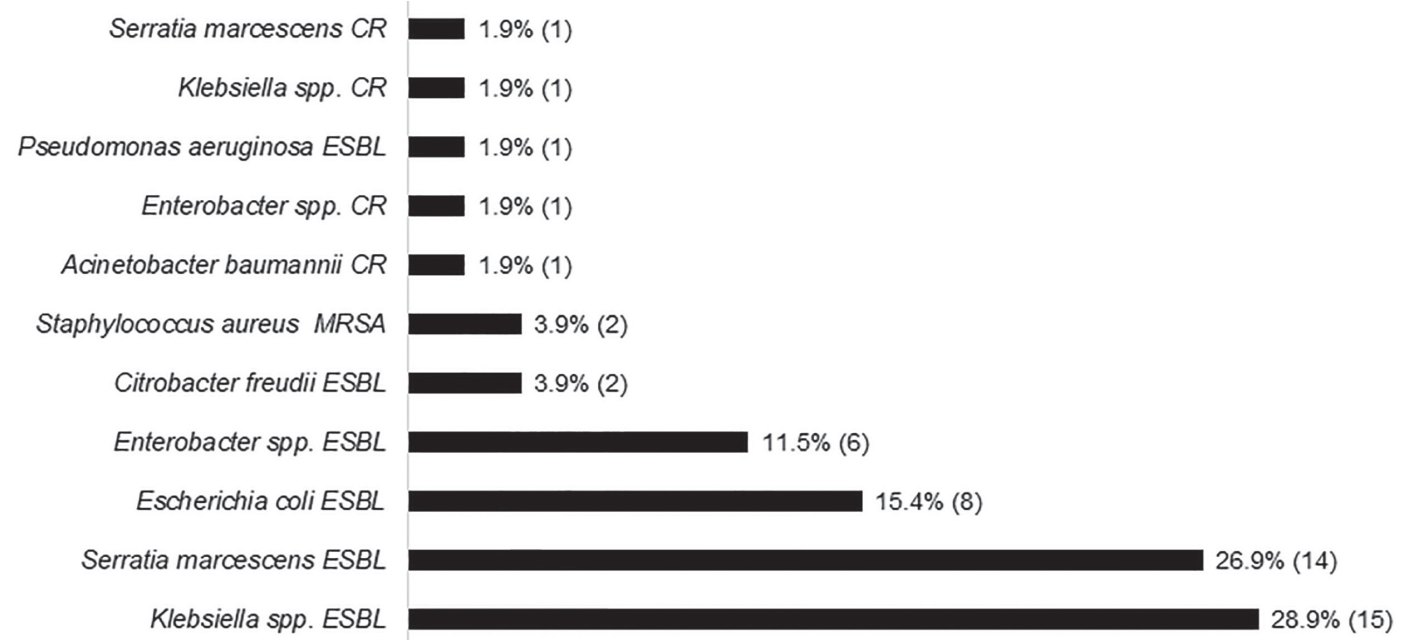

Figure 2 - Multidrug-resistant organisms isolated in colonization cultures collected at the time of infant discharge ( $n=52$ ) from a neonatal unit, Parana State, Brazil, 2014-2018. CR: Carbapenems resistant; ESBL: Extended Spectrum $\beta$-lactamase; MRSA: methicillin/oxacillin resistant Staphylococcus aureus.

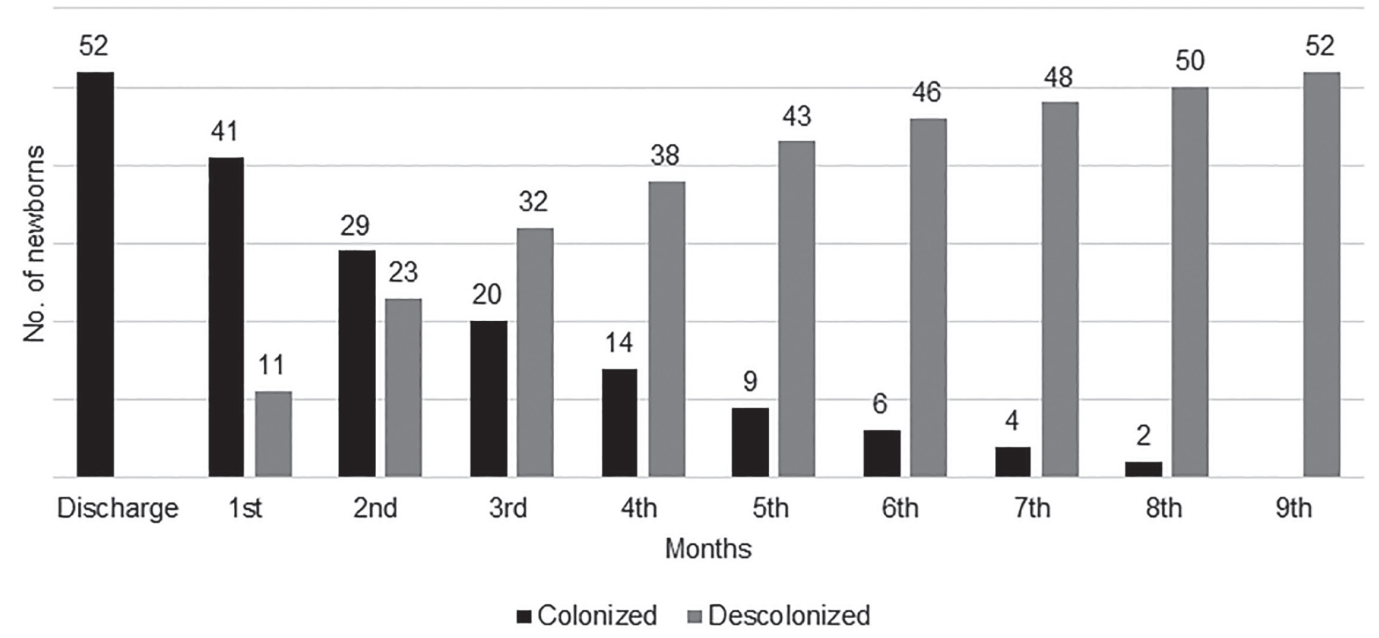

Figure 3 - Number of infants colonized and decolonized by multidrug-resistant organisms in the domiciliary context ( $n=52)$ according to the period in months after discharge, Parana State, Brazil, 2014-2018.

colonized by MDR readmitted to the NICU ${ }^{16}$. This was the only study that considered all the species of MDR, showing a mean period of 3.4 months for decolonization.

Regarding Gram-positive multidrug-resistant bacteria, only MRSA colonized infants in the current study, with an average time of 3 months for decolonization. This bacterial species is frequent in neonatal infections related to health care $^{19,29}$. Given this threat, MRSA decolonization is recommended through the use of topical antimicrobial agents, however, as mentioned earlier, this practice is not recommended for infants due to the immaturity of their epithelial barrier, potential toxicity of the medication ${ }^{19}$, as well as the risk of antimicrobial resistance and exposure to other pathogens ${ }^{13,19}$. In a cohort study conducted at a university medical center, after nasal decolonization with mupirocin and a chlorhexidine bath in infants colonized with MRSA, $38 \%$ of infants were recolonized with the same microorganism and $16 \%$ developed MRSA infection, making this practice controversial for neonatal decolonization $^{30}$.

The limitations of the study were the failure to perform swab collection at hospital discharge, as well as the impossibility of investigating factors related to the use of antimicrobial therapy at home, considering the reports of the mothers and the absence of records on the medications used. However, this study presented as strengths its methodological rigor in the follow-up of infants after hospital discharge, as well as the investigation of different MDR species within a considerable neonatal population.

The novelty of the results of this research is in line with a relevant issue in global health, the antimicrobial resistance, contributing to fill some of the gaps in knowledge regarding 


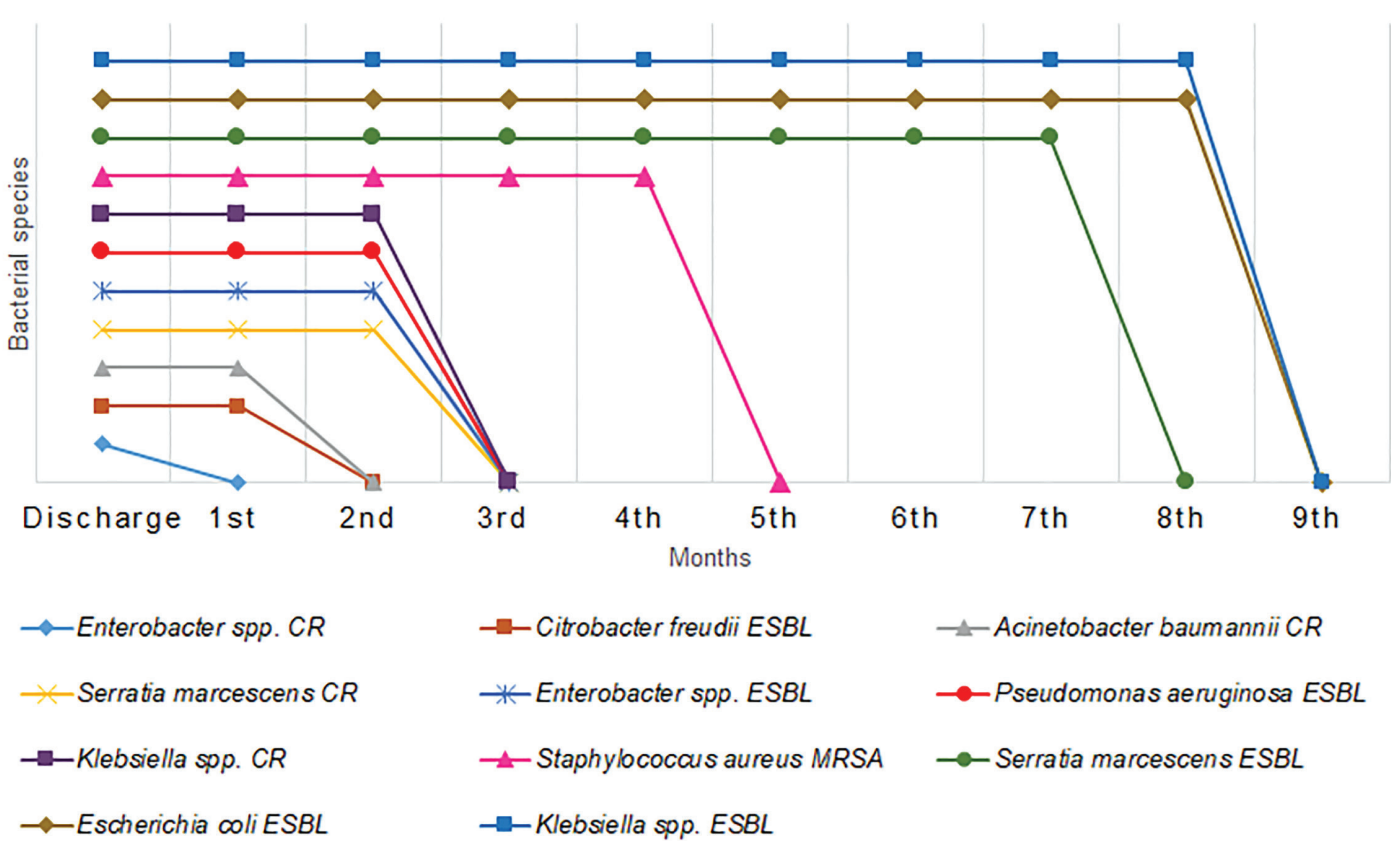

Figure 4 - Colonization period after discharge and decolonization according to multidrug-resistant organisms in infants in the domiciliary context, Parana State, Brazil, 2014-2018. CR: Carbapenems resistant; ESBL: Extended Spectrum $\beta$-lactamase; MRSA: methicillin/oxacillin resistant Staphylococcus aureus.

the period of colonization in infants by MDR after hospital discharge.

\section{CONCLUSION}

This research identified that the median period for spontaneous MDR decolonization in infants in the domiciliary setting was 3 months, considering all MDR species, and a maximum of 9 months, with a predominance of ESBL-producing Gram-negative bacteria.

\section{ACKNOWLEDGMENTS}

We are grateful to the Microbiology Laboratory and the Neonatal Intensive Care Unit of Hospital Universitario de Londrina, Universidade Estadual de Londrina.

\section{AUTHOR'S CONTRIBUTIONS}

AMS wrote the manuscript and participated in data collection and analysis; GK, EGR, SFYO, MREP conceived, designed and supervised the study, wrote and perfomed data analysis; TNANI, KOP, NAAS, RLS and LGOP performed the laboratory procedures; RR gave substantial contributions for analysis and interpretation of data; JDC, MP, ECV, LMYL and MSAS participated in study supervision and data collection. All the authors read and approved the final manuscript.

\section{FUNDING}

This study was supported by grants from Conselho Nacional de Desenvolvimento Científico e Tecnológico (CNPq) (public call 14/2014, process $\left.\mathrm{N}^{\circ} 444646 / 2014-0\right)$ and Coordenação de Aperfeiçoamento de Pessoal de Nível Superior (Financial code 01). AMS was funded by graduate scholarships from CAPES. RLS was funded by a graduate scholarships from Fundação Araucária. LMYL and SFYO were funded by research fellowships from CNPq.

\section{REFERENCES}

1. Collado MC, Rautava S, Aakko J, Isolauri E, Salminen S. Human gut colonisation may be initiated in utero by distinct microbial communities in the placenta and amniotic fluid. Sci Rep. 2016;6:23129.

2. Moles L, Gómez M, Heilig H, Bustos G, Fuentes S, de Vos W, et al. Bacterial diversity in meconium of preterm neonates and evolution of their fecal microbiota during the first month of life. PLoS One. 2013;8:e66986.

3. Valentine G, Chu DM, Stewart CJ, Aagaard KM. Relationships between perinatal interventions, maternal-infant microbiomes, and neonatal outcomes. Clin Perinatol. 2018;45:339-55.

4. Dominguez-Bello MG, Costello EK, Contreras M, Magris M, Hidalgo G, Fierer N, et al. Delivery mode shapes the acquisition and structure of the initial microbiota across multiple body habitats in newborns. Proc Natl Acad Sci USA. 2010;107:11971-5. 
5. Deweerdt S. How baby's first microbes could be crucial to future health. Nature. 2018;555:S18-9.

6. Hartz LE, Bradshaw W, Brandon DH. Potential NICU environmental influences on the neonate's microbiome: a systematic review. Adv Neonatal Care. 2015;15:324-35.

7. Itani T, Ayoub Moubareck C, Melki I, Rousseau C, Mangin I, Butel MJ, et al. Establishment and development of the intestinal microbiota of preterm infants in a Lebanese tertiary hospital. Anaerobe. 2017;43:4-14.

8. Hooven TA, Polin RA. Healthcare-associated infections in the hospitalized neonate: a review. Early Hum Dev. 2014;90 Suppl 1:S4-6.

9. Clock SA, Ferng YH, Tabibi S, Alba L, Patel SJ, Jia H, et al. Colonization with antimicrobial-resistant gram-negative bacilli at neonatal intensive care unit discharge. J Pediatric Infect Dis Soc. 2017;6:219-26.

10. Russotto V, Cortegiani A, Fasciana T, Iozzo P, Raineri SM, Gregoretti C, et al. What healthcare workers should know about environmental bacterial contamination in the intensive care unit. Biomed Res Int. 2017;2017:6905450.

11. Word Health Organization. Antimicrobial resistance. Bull World Health Organ. 1983;61:383-94.

12. Centers for Disease Control and Prevention. Biggest threats and data. [cited 2020 Feb 18]. Available from: http://www.cdc.gov/ drugresistance/threat-report-2013/index.html

13. Septimus EJ, Schweizer ML. Decolonization in prevention of health care-associated infections. Clin Microbiol Rev. 2016;29:201-22.

14. Löhr IH, Rettedal S, Natås OB, Naseer U, Øymar K, Sundsfjord A. Long-term faecal carriage in infants and intra-household transmission of CTX-M-15-producing Klebsiella pneumoniae following a nosocomial outbreak. J Antimicrob Chemother. 2013;68:1043-8.

15. Feldman N, Adler A, Molshatzki N, Navon-Venezia S, Khabra E, Cohen D, et al. Gastrointestinal colonization by KPCproducing Klebsiella pneumoniae following hospital discharge: duration of carriage and risk factors for persistent carriage. Clin Microbiol Infect. 2013;19:E190-6.

16. Haverkate MR, Derde LP, Brun-Buisson C, Bonten MJ, Bootsma MC. Duration of colonization with antimicrobial-resistant bacteria after ICU discharge. Intensive Care Med. 2014;40:56471.

17. Lucet JC, Koulenti D, Zahar JR. Persistence of colonisation with MDRO following discharge from the ICU. Intensive Care Med. 2014;40:603-5.

18. Zimmerman FS, Assous MV, Bdolah-Abram T, Lachish T, Yinnon AM, Wiener-Well Y. Duration of carriage of carbapenemresistant Enterobacteriaceae following hospital discharge. Am J Infect Control. 2013;41:190-4.

19. Nelson MU, Bizzarro MJ, Dembry LM, Baltimore RS, Gallagher PG. One size does not fit all: why universal decolonization strategies to prevent methicillin-resistant Staphylococcus aureus colonization and infection in adult intensive care units may be inappropriate for neonatal intensive care units. J Perinatol. 2014;34:653-5.

20. Siegel JD, Rhinehart E, Jackson M, Chiarello L. Management of multidrug-resistant organisms in healthcare settings, 2006. [cited $2020 \mathrm{Feb}$ 17]. Available from: https://www.cdc.gov/ infectioncontrol/pdf/guidelines/mdro-guidelines.pdf

21. Clinical and Laboratory Standards Institute. Performance standards for antimicrobial susceptibility testing. Wayne: CLSI; 2014.

22. Clinical and Laboratory Standards Institute. Performance standards for antimicrobial susceptibility testing. Wayne: CLSI; 2015.

23. Clinical and Laboratory Standards Institute. Performance standards for antimicrobial susceptibility testing. Wayne: CLSI; 2016.

24. Clinical and Laboratory Standards Institute. Performance standards for antimicrobial susceptibility testing. Wayne: CLSI; 2017.

25. Clinical and Laboratory Standards Institute. Performance standards for antimicrobial susceptibility testing. Wayne: CLSI; 2018.

26. European Committee on Antimicrobial Susceptibility Testing. Guidelines for detection of resistance mechanisms and specific resistances of clinical and/or epidemiological importance. [cited 2020 Feb 17]. Available from: http://www.eucast. org/fileadmin/src/media/PDFs/EUCAST_files/Resistance mechanisms/EUCAST_detection_of_resistance_mechanisms_ v1.0_20131211.pdf

27. Magiorakos AP, Srinivasan A, Carey RB, Carmeli Y, Falagas ME, Giske CG, et al. Multidrug-resistant, extensively drug-resistant and pandrug-resistant bacteria: an international expert proposal for interim standard definitions for acquired resistance. Clin Microbiol Infect. 2012;18:268-81.

28. Strenger V, Feierl G, Resch B, Zarfel G, Grisold A, MasoudLandgraf L, et al. Fecal carriage and intrafamilial spread of extended-spectrum $\beta$-lactamase-producing Enterobacteriaceae following colonization at the neonatal ICU. Pediatr Crit Care Med. 2013;14:157-63.

29. Popoola VO, Colantuoni E, Suwantarat N, Pierce R, Carroll $\mathrm{KC}$, Aucott SW, et al. Active surveillance cultures and decolonization to reduce Staphylococcus aureus infections in the neonatal intensive care unit. Infect Control Hosp Epidemiol. 2016;37:381-7.

30. Popoola VO, Budd A, Wittig SM, Ross T, Aucott SW, Perl TM, et al. Methicillin-resistant Staphylococcus aureus transmission and infections in a neonatal intensive care unit despite active surveillance cultures and decolonization: challenges for infection prevention. Infect Control Hosp Epidemiol. 2014;35:412-8. 